\title{
Closed rhinoplasty: effects and changes on voice - a preliminary report
}

\author{
Giuseppe Guarro, Romano Maffia, Barbara Rasile, Carmine Alfano
}

Department of Plastic and Reconstructive Surgery, University of Perugia, 06156 Perugia, Italy.

Address for correspondence: Dr. Giuseppe Guarro, Department of Plastic and Reconstructive Surgery, University of Perugia, S. Andrea delle Fratte, 06156 Perugia, Italy. E-mail: giuseppeguarro@email.it

\begin{abstract}
Aim: Effects of rhinoplasty were already studied from many points of view: otherwise poor is scientific production focused on changes of voice after rhinoplasty. This preliminary study analyzed objectively and subjectively these potential effects on 19 patients who underwent exclusively closed rhinoplasty. Methods: This preliminary evaluation was conducted from September 2012 to May 2013 and 19 patients have undergone primary rhinoplasty with exclusively closed approach (7 males, 12 females). All patients were evaluated before and 6 months after surgery. Each of them answered to a questionnaire (Voice Handicap Index Score) and the voice was recorded for spectrographic analysis: this system allowed to perform the measurement of the intensity and frequency of vowels (" $\mathrm{A}$ " and " $\mathrm{E}$ ") and nasal consonants ("N" and " $\mathrm{M}$ ") before and after surgery. Data were analysed with the Mann-Whitney test. Results: Sixteen patients showed statistically significant differences after surgery. It was detected in $69 \%$ of cases an increased frequency of emission of the consonant sounds $(P=0.046)$, while in $74 \%$ of cases the same phenomenon was noticed for vowel sounds $(P=0.048)$. Conclusion: Many patients who undergo rhinoplasty think that the intervention only leads to anatomical changes and improvement of respiratory function. The surgeon should instead accurately inform patients about the potential effects on the voice. This preliminary study reveals the significant effects of closed rhinoplasty on the human voice.
\end{abstract}

Key words:

Rhinoplasty; voice; handicap; score; spectrogram

\section{INTRODUCTION}

Closed rhinoplasty is nowadays one of the most requested aesthetic surgeries in occident. Many effects of this kind of procedure have already been studied from several points of view, otherwise in literature we found few works about the impact of exclusively closed rhinoplasty on individual and technical features of voice. ${ }^{[1-3]}$ The impact of surgery on the anatomy of the nasal cavity, the true resonance box of the phonatory system, was not deeply studied. ${ }^{[4]}$ Patients who use professionally their

\begin{tabular}{|l|l|}
\hline \multicolumn{2}{|c|}{ Access this article online } \\
\hline Quick Response Code: & Website: \\
\hline & http://www.parjournal.net \\
\cline { 2 - 3 } & \\
\hline
\end{tabular}

voices can feel the relevance of these consequences. ${ }^{[5]}$ We conducted a preliminary evaluation to study these potential effects, considering that changes on the size of nasal cavity may let airflow resistance grow. ${ }^{[6]}$ We decided to study patients who underwent a surgical procedure like closed rhinoplasty, because it allows to solve many respiratory disfunctions, but it is also a widely requested aesthetic procedure. A preliminary evaluation, conducted

This is an open access article distributed under the terms of the Creative Commons Attribution-NonCommercial-ShareAlike 3.0 License, which allows others to remix, tweak and build upon the work non-commercially, as long as the author is credited and the new creations are licensed under the identical terms.

For reprints contact: service@oaepublish.com

How to cite this article: Guarro G, Maffia R, Rasile B, Alfano C. Closed rhinoplasty: effects and changes on voice - a preliminary report. Plast Aesthet Res 2016;3:231-4.

Received: 28-07-2015; Accepted: 08-12-2015 
by our department, analyzed objectively and subjectively the potential changes brought by closed rhinoplasty on many characteristics of vocal pattern, such as frequency, tones and timbre.

\section{METHODS}

Our preliminary evaluation was conducted from September 2012 to May 2013. We studied 19 patients (7 males, 12 females), raging in ages from 19 to 56 years (mean age was 29.3 years). All of them underwent exclusively closed rhinolplasty. An informed consent and an accurate clinical history were obtained from all patients, and every single step of our evaluation was carried on through the rules of the local medical ethic committee of Umbria, Italy. Our preliminary evaluation was obtained with an observational study. Both the objective and the subjective evaluation were realized with a time series study, through a chronological sequence of data points, consisting in several measures made over a 6 months time interval. All data were analyzed with the MannWhitney test. Inclusion criteria were the professional use of voice and the purely aesthetic request for the surgery. We excluded patients affected by chronic respiratory diseases; we also excluded secondary procedures. The study was approved by the local ethical committee under the World Medical Association Declaration of Helsinki guidelines. Of our patients, $24 \%$ used their voce professionally. All 19 patients were studied before and 6 months after surgery. The same surgeon performed the 19 operations. Authors always used the closed approach for the surgical procedures, performed under general anesthesia with the supplementary infiltration of a local anesthetic with vasoconstrictor (xylocaine 1\% and epinephrine 1:100,000). The intercartilaginous incision starts the procedure, and after the dissection of vestibular skin, the operator reduces the dorsum. Lateral low-to-high osteotomies and the management of the tip, performed with a delivery approach, complete the procedure. Grafts or additional procedures were never used.

After 1 week, we removed nasal splints. This preliminary postoperative evaluation was performed 6 months after surgery (we will evaluate more patients for a longer period of time, for a stronger report). The study of the voice was performed with both objective and subjective methods. To compare the extracted data from preoperative and postoperative evaluations, the results were analyzed with the Mann-Whitney test. The objective analysis, conducted with the study on spectrograms, allowed to quantify the frequency levels of nasal consonants ("N" and "M") and vowels ("A" and "E") before and 6 months after surgery. It was conducted with a professional recording system and sounds were analysed using the PRAAT open source software. Voices were analyzed in frames of $3 \mathrm{~s}$ and for every single sound we extracted a spectrogram and studied it through a spectrographic analysis. Every recording was performed in a quiet room, using the professional recording system at a constant distance from mouth $(12 \mathrm{~cm})$. All data, expressed as \pm standard deviation, were analyzed with the Mann-Whitney test and values were compared before and 6 months after the intervention. All data with a $P$ value of 0.05 or less were considered statistically significant for the preliminary report.

The subjective evaluation, instead, was supported by a questionnaire, translated in Italian. The questionnaire was a modified version of the Voice Handicap Index Score ${ }^{[7,8]}$ and helped us to study the subjective changes. It is composed by 3 legs, technical, structural and perceptive: a greater handicap is reflected by a greater score. Technical leg is about effects of vocal pattern on work life. The structural leg is about any personal detected disorders. Perceptive leg comprises questions about the personal perception of the effects on voice after rhinoplasty. Patients answered this questionnaire before and 6 months after surgery. Results were compared in total score and separately for each area of questions.

\section{RESULTS}

The 19 patients enrolled for the study were observed before and 6 months after surgery (this is a preliminary report, we will continue with a long-term evaluation in future, with more patients). For the subjective evaluation, our modified version of Voice Handicap Index Scores helped us to evaluate several characteristics of the personal perception of voice. We separately scored and compared each area of the translated questionnaire.

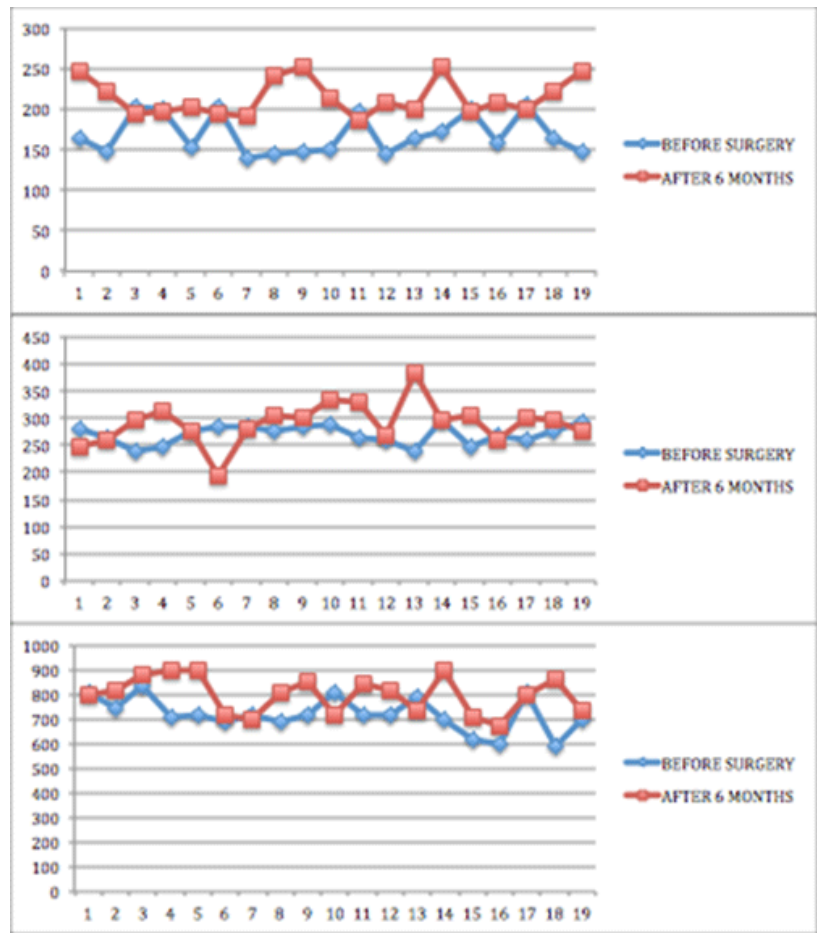

Figure 1: Frequencies of " $\mathrm{M}$ " consonant sound (top), "N" consonant sound (middle) and "A" vowel sound (bottom) before and 6 months after surgery. Data are expressed in Hertz 
We noticed a statistically significant difference in data derived from the answers 6 months after surgery $(P$ $=0.047$ ). Patients noticed effects on voice not only in general, but also for every single area of questions. The increased score suggests that vocal features significantly change after closed rhinoplasty.

The objective evaluation was conducted with a spectrographic analysis for the 4 sounds ("A"/"E" vowels, "N" and "M" consonants), before and 6 months after surgery. The frequency of every single spectrogram $(\mathrm{Hz})$ was the main considered parameter. We have to underline that data extracted from the spectrographic analysis of vowel sounds clearly show the improved vocal pattern in patients undergoing closed rhinoplasty. We found an increased frequency of emission of consonant sounds in $69 \%$ of cases $(P=0.046)$, and in $74 \%$ of cases for vowels $(P=0.048)$. The results of this analysis are shown in Figure 1. We didn't detect major complications in the immediate postoperative period (2 weeks).

\section{DISCUSSION}

Changes on voice after closed rhinoplasty were the main target of this preliminary report: we found statistically significant effects on several vocal features.

In literature, we didn't find any work about the impact of exclusively closed rhinoplasty on individual and technical features of voice. ${ }^{[9-12]}$ This preliminary evaluation begins from the principle that changes in nasal cavity volume may bring effects to the resonance system and frequency of several vocal sounds. ${ }^{[13-16]}$

We conducted a preliminary report and enrolled 19 patients which underwent a closed primary rhinoplasty.

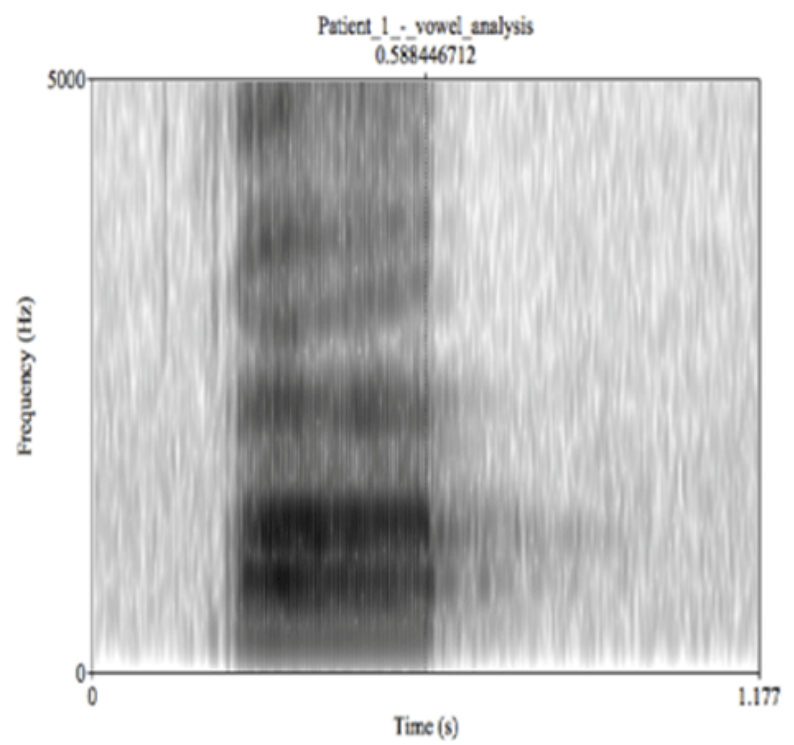

Figure 2: An example of a spectrogram analyzed in our preliminary report
We didn't include open procedures because our target was an evaluation after a single and standardized surgery. Objective and subjective analyses supported this evaluation, the first one performed with a spectrographic study of vocal sounds frequencies (data expressed in Hertz) before and 6 months after surgery, the second one supported by the Italian version of the "Voice Handicap Index Score".

The objective study, performed with an open source software and a professional recording system, helped us to notice effective changes on intensity and frequency of voice after surgery. This evaluation was performed again after 6 months. The Mann-Whitney test allowed us to analyze data. An example of a spectrogram from our study is shown on Figure 2.

Data extracted from the spectrographic analysis let us discover a statistically significant change of the frequency emission for the "A" and "E" vowels and the "N"/"M" consonants (results with data expressed in Hertz are summarized on Figure 1).

The subjective evaluation showed significant changes about the perception of voice after this kind of surgery ( $P$ $=0.047$ ). This evaluation helped us to study the impact of these changes on the professional and everyday life of the 19 subjects. This result, although it represents the first and preliminary step of our evaluation, is statistically significant.

In our opinion, these changes could be caused by the lateral low-to-high osteotomies performed during the surgery.

Several characteristics of vocal pattern, according to our preliminary evaluation, can be statistically changed by this kind of surgery. The subjective analysis reveals how surgery can change the personal and ideal perception of voice. The objective evaluation helped us to notice differences in sound frequency and amplitude after surgery. Bringing the focus of our study to everyday life, we can say that every surgeon who performs a closed rhinoplasty should accurately talk to patients about potential changes on the quality of voice, first of all through the informed consent. Limitations of our study were the small series of patients and the relatively short period of evaluation. We will evaluate more patients for a longer period of time, in order to confirm the results of our preliminary report.

\section{Financial support and sponsorship} Nil.

\section{Conflicts of interest}

There are no conflicts of interest.

\section{REFERENCES}

I. Brandt MG, Rotenberg BW, Moore CC, Bornbaum CC, Dzioba A, 
Glicksman JT, Doyle PC. Impact of nasal surgery on speech resonance. Ann Otol Rhinol Laryngol 20।4;123:564-70.

2. Mora R, Jankowska B, Dellepiane M, Mora F, Crippa B, Salami A.Acoustic features of voice after septoplasty. Med Sci Monit 2009;15:CR269-73.

3. Behrman A, Shikowitz MJ, Dailey S. The effect of upper airway surgery on voice. Otolaryngol Head Neck Surg 2002; 127:36-42.

4. Ozbal Koc EA, Koc B, Ercan I, Kocak I, Tadihan E, Turgut S. Effects of septoplasty on speech and voice. J Voice 2014;28:393.

5. Natour YS, Sartawi AM, Al Muhairy O, Efthymiou E, Marie BS. Emirati teachers' perceptions of voice handicap. J Voice 2016;30:378.el3-20.

6. Rosanowski F, Eysholdt U. Phoniatric aspects in cleft lip patients. Facia Plast Surg 2002; 18:197-203.

7. Seifpanahi S, Jalaie S, Nikoo MR, Sobhani-Rad D. Translated versions of voice handicap index (VHI)-30 across languages: a systematic review. Iran J Public Health 2015;44:458-69.

8. Arffa RE, Krishna P, Gartner-Schmidt J, Rosen CA. Normative values for the voice handicap index-10.J Voice 2012;26:462-5.

9. Chen W,Woo P, Murry T.Vocal fold vibratory changes following surgical intervention. J Voice 2016;30:224-7.
10. Behlau M, Madazio G, Moreti F, Oliveira G, Dos Santos Lde M, Paulinelli $B R$, Couto Junior Ede B. Efficiency and cutoff values of self-assessment instruments on the impact of a voice problem. J Voice 2016;30:506.e918.

II. Behlau M, Hogikyan ND, Gasparini G. Quality of life and voice: study of a Brazilian population using the voice-related quality of life measure. Folia Phoniatr Logop 2007;59:286-96.

12. Datta R. Occupational hazards of the emerging voice professions. J Laryngol Voice 2013;3:I-2.

13. Faheem RS, Botros RR, Shoker SA, Azab SN. Voice acoustic changes after uvulopalatopharyngo-plasty surger. J Laryngol Voice 2014;4:53-7.

14. Desai V, Mishra P. Voice therapy outcome in puberphonia. J Laryngol Voice 20I 2;2:26-9.

15. Elmiyeh B, Dwivedi RC, Jallali N, Chisholm EJ, Kazi R, Clarke PM, Rhys-Evans $\mathrm{PH}$. Surgical voice restoration after total laryngectomy: an overview. Indian J Cancer 2010;47:239-47.

16. Chirilă M, Țiple C, Dinescu FV, Mureșan R, Bolboacă SD. Voice rehabilitation with tragal cartilage and perichondrium after vertical partial laryngectomy.J Res Med Sci 20I5;20:323-8. 